\title{
MOBILITY OF NURSING SPECIALISTS FOR THE IMPROVEMENT OF THEIR PROFESSIONAL SKILLS AND COMPETENCIES
}

\author{
Aneta Dokova ${ }^{1}$, Silviya Borisova ${ }^{2}$, Todorka Kostadinova ${ }^{3}$, Svetlana \\ Panayotova $^{1}$ \\ 1) Department of International Relations, Medical University - Varna, Bulgaria. \\ 2) Department of Nursing Care, Faculty of Public Health, Medical University \\ - Varna, Bulgaria. \\ 3) Department of Economics and Healthcare Management, Faculty of Public \\ Health, Medical University -Varna, Bulgaria.
}

\section{SUMMARY}

Purpose: The purpose of this study is to follow-up the development of the students' and teachers' mobilities within "Erasmus+" and the impact of the training on their professional skills and competences.

Material and methods: The study covers the period 2011-2018 in which Medical University "Prof. Paraskev Stoyanov" of Varna organized a total of 78 mobilities according to 19 "Erasmus+" agreements for mobilities of students and teachers from the Faculty of Public Health, 9 agreements for students in the specialty of nursing, 7 "Erasmus+" agreements for students in the specialty of midwifery, and 3 agreements for bilateral academic cooperation with partner universities. After the completion of the mobilities, the students' answered the questionnaire accompanying their final report, in which they give their feedback and evaluation of the fulfilled practices.

Results: The students' and teachers' mobilities in the specialties of nursing and midwifery are presented by specialty, number and countries. An analysis is provided of the feedback and evaluation of the participants in the mobilities about the benefits related to their professional qualification and future career. Recommendations are made for an adequate response of the university education and the professional challenges in front of the future nurses and midwives.

Conclusion: The increased interest to the participation in mobilities by the students of nursing care is evidence of their motivation to improve their professional skills and competences and is a prerequisite for a better quality of health care in Bulgaria as well as competitiveness within the European Union.

Key words: students of nursing management, education, mobility, qualification, internationalization

\section{INTRODUCTION}

Healthcare systems across the world are increasingly challenged by workforce shortages and misdistribu- tion of skills. Yet, no comprehensive European approach to health human resources policy exists, and action remains fragmented [1]. There is an overall lack of integrated health human resources approaches as a major obstacle of efficient health human resources planning Five dimensions of integration in health human resources policy are needed: system, occupational, sector, gender, and sociocultural integration. Yet Europe is highly diverse, and there is a need for a strategic health human resources perspective capable of bridging many different health human resources policies and planning systems as well as combining national and European solutions efficiently [1].

The expected deficits are especially critical for certain health professions and specialisations, among which nursing, care for the elderly and general practices. In addition, in almost all the European countries the geographical distribution of the health professionals is irregular, which is manifested chiefly in shortage in the rural and sparsely populated regions $[2,3]$. The lack of a sufficient number of health professionals is further aggravated by the fact that their skills and competences often are not up to the challenges of the changing health needs of the population [4].

In order to meet the need for revisiting the educational goals of the specialists in nursing care, since 2000 Medical University "Prof. Dr Paraskev Stoyanov" of Varna has been conducting an exchange of students and academic staff under "Socrates-Erasmus" programme. In 2007, the Medical University obtained an extended university charter "Erasmus", and in December 2013, the Medical University was granted a charter to work within the new "Erasmus+" programme for the period 2014-2020.

The development of internal (within the country) and international cooperation is one of the priorities of the Faculty of Public Health (FPH) for the specialties of nursing and obstetrics. The Faculty has created all the necessary conditions for students' and academic staff mobility through signed agreements for partnerships, including for students' and teachers' exchange with a number of European universities, which enable carrying out of 
trainings, internships and practices in foreign higher schools. Alongside with the "Erasmust" programme mobilities during the students' studies, mobilities can be carried out within the framework of the bilateral university agreements.

The study was aimed at following the development of students' and academic staff mobility within "Erasmus" programme and its impact on their professional skills and competences.

\section{MATERIAL AND METHODS}

In the period 2011-2018 the "Erasmus+" Office at the Department of International Relations organized a total of 86 mobilities fulfilled by specialists of nursing care - nurses and midwives and training within bilateral cooperation agreements with partner universities. Currently, the Medical University of Varna is carrying out 78 mobilities according to 19 "Erasmus+" agreements for students and academic staff of the Faculty of Public Health, of which 9 agreements for the students from the specialty of nursing, 7 "Erasmus+" agreements for students from the specialty of obstetrics and 3 bilateral agreements with partner universities. After the completion of the mobility, the students fill in a questionnaire for their final report in which they evaluate the accomplished mobility. Our purpose was to study their assessment of the benefits for their professional qualification and future career.

\section{RESULTS}

Students' mobility from the specialty of nursing under "Erasmus"/“Erasmus+" programme

For the period 2011-2018, agreements for students' exchange from the specialty of nursing under "Erasmus"/ "Erasmus+" programme have been concluded with the following institutions:

- University of Glanmorgan (University of South Wales) (United Kingdom)
- Tallinn Health Care College (Estonia)

- Polytechnical University in Ancona (Italy)

- "St Kliment Ohridski" University in Bitola (Macedonia)

- Western Norway University îf Applied Sciences HVL in Stord/Haugesund (Norway)

- Jan Grodek State Vocational Academy in Sanok (Poland)

- Trakya University in Edirne(Turkey)

- Kastamonu University (Turkey)

- Biruni University in Istanbul (Turkey).

The selection of the candidates for participation in students' mobility under "Erasmus+" programme from the Medical University of Varna is based on competition. The students have to meet the following criteria: academic results, language proficiency, well-argued motivation of the candidate for participation in mobility, communicative skills, scientific activity (participation in scientific research, publications and participation in scientific events, including position in authors' research teams), activities to the benefit of society, sports achievements, initiatives, etc.

For selection purposes, interviews are organized with all students who have expressed their wish to participate in the mobility, after which the best are approved and distributed in the respective universities. A set of documents is prepared to ensure the better organization of the mobilities, including application forms for incoming and outgoing students, types of documents for recognition and confirmation of the training activities, etc.

In the framework of "Erasmus/Erasmus+" programme for the period 2011 - 2018, 31 students from the specialty of nursing visited and were trained in the following countries: Turkey - 20, Norway - 6, United Kingdom - 3 and Macedonia - 2. Detailed information is provided in Table 1 and Figure 1.

Table 1. Outgoing students' mobility from MU-Varna for the specialty of nursing during the period 2011-2018

\begin{tabular}{|l|c|l|}
\hline Academic year & $\begin{array}{c}\text { Number of } \\
\text { mobilities }\end{array}$ & Country \\
\hline $2011 / 2012$ & 3 & Turkey - 2; United Kingdom - 1 \\
\hline $2012 / 2013$ & 3 & Turkey - 2; United Kingdom - 1 \\
\hline $2013 / 2014$ & 6 & Turkey - 4; United Kingdom - 1; Norway - 1 \\
\hline $2014 / 2015$ & 3 & Turkey - 2; Norway - 1 \\
\hline $2015 / 2016$ & 11 & Turkey - 7; Norway - 2; Macedonia - 2 \\
\hline $2016 / 2017$ & 1 & Norway - 1 \\
\hline $2017 / 2018$ & 4 & Turkey - 3; Norway -1 \\
\hline total 2011-2018 & $\mathbf{3 1}$ & $\mathbf{4}$ countries \\
\hline
\end{tabular}


Fig. 1. Country distribution of outgoing students' mobility for the specialty of nursing under "Erasmus/ Erasmus+" programme during the period 2011-2018

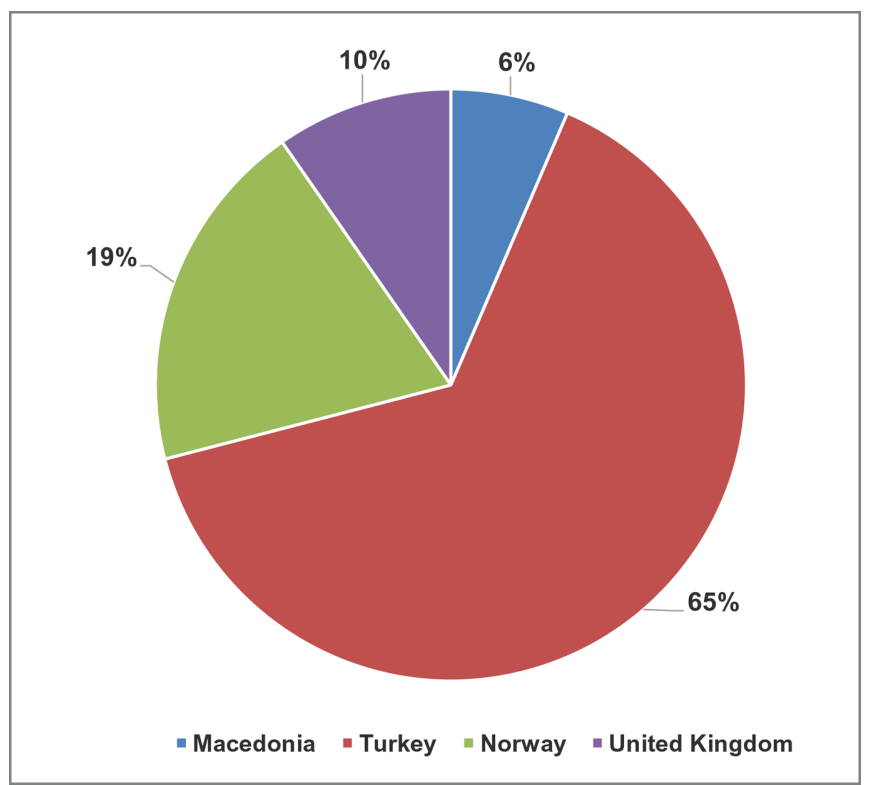

The similarity of the curricula in the higher schools in which the specialty is studied and the application of the European credit transfer system create favourable opportunities for the students' mobility in the country, too. A Commission has been set up at the Medical University of Varna for the recognition of credits obtained in another higher school [11].

In February 2014, an Intensive Training Course was organized within a project in the University of Savonia in Kuopio (Finland). It was aimed at students' training in the field of the management of chronic diseases in health and social care ESSI (Empowering Service User through Support and Involvement Chronic Illness Management). Two instructors, five pre-selected students from the specialty of nursing and two from the specialty of healthcare management participated.

Exchange under bilateral agreements for academic cooperation

The agreement for academic cooperation with First Moscow State Medical University "I. M. Sechenov" in Mos- cow (Russia) envisaged the exchange of students studying in the Bachelor's and Master's programmes of the Faculty of Public Health.

In 2015, one student in the specialty of nursing carried out a two-week summer practice at First Moscow State Medical University "I. M. Sechenov" in Moscow. The practice was conducted outside "Erasmus" programme in accordance with the working programme for the academic 2014/ 2015, which is an Annex to the agreement.

According to the agreement for academic cooperation with the North Western State Medical University "I. I. Mechnikov" in St. Petersburg (Russia) and the working programme to it for the academic 2017/2018, the students in the Master's programmes of the Faculty of Public Health can opt for two-week summer practices.

In the bilateral agreement between Medical University of Varna and Kharkov National Medical University (Ukraine) for the academic 2017/2018 two-week summer practices are planned for the students in the specialties of nursing, midwifery, nursing management, public health, and healthcare management.

Students' mobility from the specialty of midwifery under "Erasmus"/"Erasmus+" programme

For the period 2011-2018, under "Erasmus/Erasmus+" programme the Medical University of Varna has had working agreements with the following higher medical schools:

- Tallinn Health Care College (Estonia)

- Polytechnical University in Ancona (Italy)

- "St. Kliment Ohridski”" University in Bitola (Macedonia)

- Jan Grodek State Vocational Academy in Sanok (Poland)

- Trakya University in Edirne(Turkey)

- Biruni University in Istanbul (Turkey)

- Ege University in Izmir (Turkey).

The selection of the candidates in the specialty of midwifery for participation in students' mobility under "Erasmus+" programme is carried out according to the same principles as for the students in the specialty "nursing" and is organized in a similar way.

In the framework of "Erasmus" programme, during the period 2011-2018, 24 students in the specialty of midwifery visited and were trained in partner universities in Turkey, Italy and Macedonia. The mobility of the future midwives is shown in Table 2 and Figure 2.

Table 2. Outgoing students' mobility from MU-Varna for the specialty of midwifery during the period 20112018

\begin{tabular}{|l|c|l|}
\hline Academic year & Number of mobilities & Country \\
\hline $2011 / 2012$ & 2 & 2- Turkey \\
\hline $2012 / 2013$ & 0 & \\
\hline $2013 / 2014$ & 4 & Turkey - 3; Italy - 1 \\
\hline $2014 / 2015$ & 5 & Turkey - 5 \\
\hline $2015 / 2016$ & 2 & Turkey - 2 \\
\hline $2016 / 2017$ & 6 & Turkey - 5; Macedonia - 1 \\
\hline $2017 / 2018$ & 5 & Turkey - 4; Macedonia - 1 \\
\hline total 2011-2018 & 24 & 3 countries \\
\hline
\end{tabular}


Fig. 2. Country distribution of outgoing students' mobility for the specialty of midwifery under "Erasmus/ Erasmus+" programme during the period 2011-2018

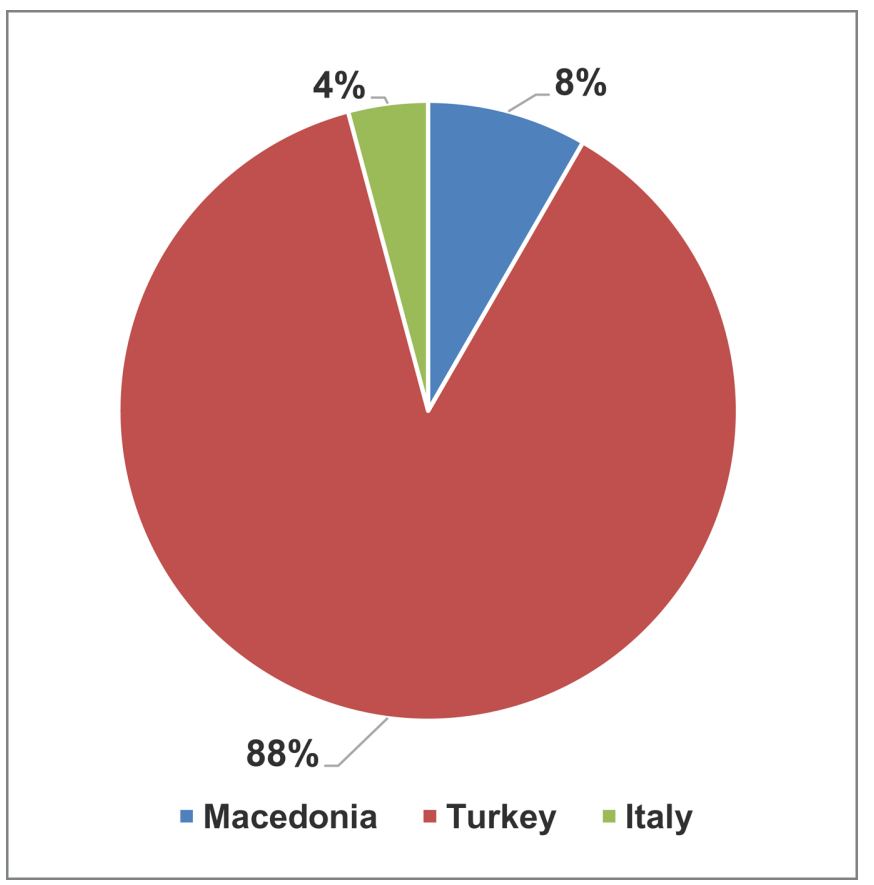

Table 3 shows the general distribution of the students' mobility in the specialties of nursing and midwifery by academic years and countries.

Table 3. Outgoing students' mobility under "Erasmus" programme, specialties of nursing and of midwifery at the Faculty of Public health

\begin{tabular}{|l|c|l|}
\hline Academic year & $\begin{array}{c}\text { Number of } \\
\text { mobilities }\end{array}$ & Country \\
\hline $2011 / 2012$ & 5 & Turkey - 4; United Kingdom - 1 \\
\hline $2012 / 2013$ & 3 & Turkey - 2; United Kingdom -1 \\
\hline $2013 / 2014$ & 10 & Turkey - 7; United Kingdom - 1; Norway - 1; Italy - 1 \\
\hline $2014 / 2015$ & 8 & Turkey - 7; Norway - 1 \\
\hline $2015 / 2016$ & 13 & Turkey - 9; Norway - 2; Macedonia - 2 \\
\hline $2016 / 2017$ & 7 & Turkey - 5; Norway - 1; Macedonia - 1 \\
\hline $2017 / 2018$ & 9 & Turkey - 7; Norway - 1; Macedonia - 1 \\
\hline total 2011-2018 & 55 & 5 countries \\
\hline
\end{tabular}

Mobility of Academic Staff from the Faculty of Public health under "Erasmus/Erasmus+" programme

In addition to the above agreements, the teachers from the Faculty of Public Health can carry out mobilities according to agreements with the following universities:

- University of applied Sciences in Berlin (Germany)

- Savonia University of Applied Sciences in Kuopio (Finland) (Latvia)

- Riga Medical College of the University of Latvia

- Lithuanian University of Health Sciences in Kaunas (Lithuania)

- Polytechnic Institute of Setúbal (Portugal)

- Istanbul University (Turkey)

- T.C. Istanbul Sisli Vocational School (Turkey)

- Süleyman Demirel Universitesi in Isparta (Turkey)
- Maastricht University (the Netherlands).

During the period 2010-2018, 23 members of the academic staff of the Faculty of Public Health carried out mobilities in foreign higher schools under "Erasmus/ Erasmus+" programme:

2011/2012 in Trakya University in Edirne (Turkey) - four teachers;

2012/2013 in the University College in Stord/ Haugesund (Norway) - two teachers;

2013/2014 in the University of Maastricht (the Netherlands) - three teachers;

2014/2015 in the University of Luxemburg - three teachers and in "St. Kliment Ohridski" University - Bitola (Macedonia) - three teachers;

2015/2016 in the University of Gdansk (Poland) three teachers; 
2016/2017 in the Polytechnical Institute in Setubal (Portugal) - three teachers, and

2017/2018 in "Maltepe" University in Istanbul (Turkey) - two teachers.

Parallel to the outgoing teacher's mobilities, in the period 2011-2018, the Medical University of Varna organized and hosted the incoming mobilities of six members of the academic staff from universities in Turkey, Macedonia and Belgium who were trained or were guest lecturers at the Faculty of Public Health under "Erasmus/Erasmus+" programme.

Feedback and assessment of the acquired professional skills and competences as a result of the fulfilled mobilities.

It is evident from the questionnaires completed by the students in the specialties of nursing and midwifery that the participants assess very highly the mobilities and very high satisfaction are registered by them with the acquired knowledge, skills and competences.

The students are most satisfied with the acquisition of new professional skills, the mastering of new methods and techniques and the practice they have accumulated. Some of the respondents describe in detail the wards to which they were assigned, the tasks they had to perform in the foreign hospitals and the competences they were authorized to practice. The students report that they were very well accepted, the partners were supportive and cooperative, and the organization of the clinical practices was excellent.

The second position in the students' assessment of their personal outcomes from the conducted mobilities is occupied by the improvement of the future prospects for employment and career development. Furthermore, 98\% of the respondents believe that such mobilities increase the chances for professional development not only in Bulgaria but also abroad and report that they would seek for career development outside the Bulgarian borders.

Another benefit registered by the students from their mobilities under "Erasmust" programme is the acquaintance with the health care systems in other countries and the work organization which they deem useful in their professional practice.

Cultural exchange which is one of the main objectives of "Erasmus/Erasmust" programme is ranked among the main advantages, reported by the students of nursing and midwifery. The familiarization with other cultures, history and lifestyle as well as with different organizational culture of the foreign universities and hospitals is indisputably important for the development of students' professional culture and education.

Last but not least, the students who had taken part in "Erasmus" mobility report about the positive impact of the practices on the improvement of their language skills. The possibility of practicing a foreign language is closely linked with the establishment of contacts and facilitates the professional communication with the mentors, patients and colleagues.

\section{Recommendation for the academic training}

In their reports, the members of the academic staff recommend the offering of a greater number of mobilities for instructors in the specialty of nursing care since it enriches their experience as teachers with new techniques and methods of teaching as well as their knowledge about the organization of nursing care in the other European countries.

A similar recommendation is offered by the students who do not necessarily have an adequate self-assessment as to whether and how far they meet the "Erasmus+" requirements. Yet another issue with the mobility is the fact that it is planned a year in advance and the students have to be able to plan their time, resources and career development.

One of the limitations for carrying out more mobilities for the students of nursing and midwifery is the inadequate language proficiency. The mobility analysis indicates that Turkey is the most preferred destination for the students of nursing and midwifery because a significant number of the students in these specialties are Bulgarian born of Turkish origin. For the majority of the remaining students, the lack of proficiency in the English language is an impediment for benefiting from the opportunities provided by "Erasmus+" programme for improving the professional competences of the future nurses and midwives. Language proficiency is one of the many competences developed by the specialists in nursing care and therefore, it has to be emphasized during the academic training.

\section{DISCUSSION}

About 90 nursing students from two research universities in Sweden and the United States per semester over several semesters participate in virtual international exchanges that open opportunities for innovative communication and learning contexts across nations and cultures [5]. Internationalization of higher education involving information and communication technology such as e-learning is so much more than students and teachers' mobility. It should receive more attention to support faculty and student collaboration, learning, and professional development.

The content analysis of 20 semi-structured interviews with Indian clinical nurses working in Italy for more than one year mainly in private organizations identifies four themes: i) aspects of professional integration and working experience, ii) intra- and interprofessional relationships and perceptions of the Regulatory Nursing Board of IPASVI Centre of Excellence for Nursing Scholarship in Rome, Italy, iii) initial nursing education and continuous professional development and iv) perceptions of social integration [6]. For Indian nurses in Italy, emigration is important to gain opportunities to expand economic and social privileges as well as escape from historical assumptions of the stigma associated with nursing work, especially for women.

Eight nursing programmes located in seven countries (Belgium, Denmark, Greece, Norway, Poland, Portugal and Italy) are approached in order to compare the clinical competence assessment processes and instruments adopted for nursing students during their clinical placement abroad [7]. 
Thro. Most of them are categorized as 'Technical skills' $(n=60)$, 'Self-learning and critical thinking' $(n=27)$ and 'Nursing care process' $(n=25)$ competences.

A systematic review of five peer-reviewed articles published in any language between 2000 and 2014 and retrieved from seven electronic databases such as CINAHL, MEDLINE Ovid, Scopus, the Web of Science, Academic Search Premiere, ERIC, and the Cochrane Library describing mentors' experiences of international healthcare students' learning in a clinical environment is performed [8]. A conclusion is drawn that a positive intercultural mentor enhances reciprocal learning by improving the experience of international healthcare students and reducing stress in the clinical environment. Integrating international healthcare students into work with domestic students is important for the avoidance of discrimination.

Health inequities within Nigeria mirror the geographical disparities in human resources for health distribution and are worsened by the emigration of Nigerian nurses to developed countries such as the United States and the United Kingdom [9]. Nigerian nurses are motivated to emigrate to work in healthier work environments, improve their economic prospects, and advance their careers. Like other migrant African nurses, they experience barriers to integration, including racism and discrimination, in receiving countries.

A panel of expert nurse educators from 11 countries such as Croatia, Czech Republic, England, Iceland, Ireland, Italy, Poland, Serbia, Slovenia, Spain, and the USA develops a questionnaire containing both quantitative and qualitative questions about the roles occupied by clinical mentors across countries [10]. In all these countries, there are at least two types of clinical mentorship dedicated to undergraduate nursing students: offered by higher institutions and by health care providers. While it is imperative to have respect for the different national traditions in undergraduate nurse education, nursing workforce globalization and greater opportunities for student mobility during the undergraduate education suggests that in areas such as clinical mentorship, jurisdictions, particularly within the European Union, should work towards greater system harmonization.

The lack of standardization for nursing specializations across the European Union leads to absent mobility across countries [11]. Nurse specialists can be regarded as operating at nursing's 'leading edge'. It is now time for European Union nurses to look beyond the common standards for pre-registration courses and consider the development of common standards for specialist nursing.

For nursing students, studying abroad within academic mobility programmes facilitates the development of cultural sensitivity so that they may care appropriately for an increasingly multicultural patient population in their own countries [12]. A Brazilian 'study abroad' student nurse's experience of studying a 'communication and therapeutic relationships' module in an Irish university is described.

The emigration of Portuguese health professionals is stimulated by the difficulty for recently graduated nurses, dentists and diagnostic and therapeutic technicians to find employment, low salaries in the public and private sectors, heavy workloads, remuneration not related to performance and poor career prospects [13].

Nurses comprise a large sector of the global health workforce. They are called upon to provide a significant portion of nursing and health care and thus play an integral role in the global health care economy [14]. In order to meet global health care needs, nurses often move within and among countries, creating challenges and opportunities for the profession, health care organizations, communities, and nations. Researchers, policy makers, and industry and academic leaders must, in turn, grapple with the impacts of globalization on the nursing and health care workforce.

\section{CONCLUSION}

The mobility of students and academic staff increases the competences, and the motivation for work significantly improves the quality and the opportunities for career development [12]. The mobility participants adapt their knowledge and skills in accordance with the international requirements and medical standards. Mobility enhances the international cooperation between the Medical University of Varna and its partners. The increasing interest to participate in mobilities on behalf of the students studying for nurses and midwives is evidence for their motivation to improve their professional skills and competences, which in its turn, is a prerequisite for the improvement of the quality of nursing care in Bulgaria as well as competitiveness in the European Union.

\section{REFERENCES:}

1. Kuhlmann E, Batenburgb R, Groenewegenb P, Larsenc C. Bringing a European perspective to the health human resources debate: A scoping study. Health Policy. 2013 Apr; 110(1):6-13. [PubMed] [Crossref].

2. Kroezen M, Dussault G, Craveiro I, Dieleman M, Jansen C, Buchan J, et al. Recruitment and retention of health professionals across Europe: A litera- ture review and multiple case study research. Health Policy. 2015 Dec;119 (12):1517-28. [PubMed] [Crossref].

3. Buchan J, Twigg D, Dussault G, Duffield C, Stone PW. Policies to sustain the nursing workforce: an international perspective. Int Nurs Rev. 2015 Jun;62(2):162-70.

[PubMed]

[Crossref].

4. Sarkis N, Mwanri L. The role of information technology in strengthening human resources for health: the case of the Pacific open learning health network. Health Educ. 2013 Dec 20; 114(1):67-79. [Crossref].

5. Wihlborg M, Friberg EE, Rose KM, Eastham L. Facilitating learning through an international virtual collaborative practice: A case study. Nurse Educ Today. 2018 Feb;61:3-8. 


\section{[PubMed] [Crossref]}

6. Stievano A, Olsen D, Tolentino Diaz Y, Sabatino L, Rocco G. Indian nurses in Italy: a qualitative study of their professional and social integration. J Clin Nurs. 2017 Dec;26(2324):4234-4245. [PubMed] [Crossref]

7. Tommasini C, Dobrowolska B, Zarzycka D, Bacatum C, Bruun AM, Korsath D, et al. Competence evaluation processes for nursing students abroad: Findings from an international case study. Nurse Educ Today. 2017 Apr;51:41-47. [PubMed] [Crossref]

8. Mikkonen K, Elo S, Tuomikoski AM, Kääriäinen M. Mentor experiences of international healthcare students' learning in a clinical environment: A systematic review. Nurse Educ
Today. 2016 May;40:87-94. [PubMed] [Crossref]

9. Salami B, Dada FO, Adelakun FE. Human resources for health challenges in Nigeria and nurse migration. Policy Polit Nurs Pract. 2016 May;17(2):7684. [PubMed] [Crossref]

10. Dobrowolska B, McGonagle I, Kane R, Jackson CS, Kegl B, Bergin $\mathrm{M}$, et al. Patterns of clinical mentorship in undergraduate nurse education: A comparative case analysis of eleven EU and non-EU countries. Nurse Educ Today. 2016 Jan;36: 44-52. [PubMed] [Crossref]

11. Ranchal A, Jolley MJ, Keogh J, Lepiesová M, Rasku T, Zeller S. The challenge of the standardization of nursing specializations in Europe. Int
Nurs Rev. 2015 Dec;62(4):445-452. [PubMed] [Crossref]

12. de Oliveira AK, Tuohy D. Communication and nursing: a studyabroad student's reflections. Br J Nurs. 2015 Nov 26-Dec 9;24(21):1080-2, 1084. [ubMed] [Crossref]

13. Ribeiro JS, Conceição C, Pereira J, Leone C, Mendonça P, Temido M, et al. Health professionals moving to... and from Portugal. Health Policy. 2014 Feb;114(2-3):97-108. [PubMed] [Crossref]

14. Jones CB, Sherwood GD. The globalization of the nursing workforce: Pulling the pieces together. Nurs Outlook. 2014 Jan-Feb;62(1):5963. [PubMed] [Crossref]

Please cite this article as: Dokova A, Borisova S, Kostadinova T, Panayotova S. Mobility of Nursing Specialists for the Improvement of Their Professional Skills and Competencies. J of IMAB. 2018 Oct-Dec;24(4):2210-2216.

DOI: https://doi.org/10.5272/jimab.2018244.2210

Received: 01/06/2018; Published online: 19/10/2018

\author{
Address for correspondence: \\ Aneta Dokova, PhD \\ Department of International Relations, Medical University of Varna \\ 55, Marin Drinov Str., Varna 9002, Bulgaria \\ E-mail: dokova@mu-varna.bg
}

